\title{
The Reasons that Companies Prefer Certain Media Promotional Aspects
}

\author{
Rajan Arapi \\ Phd (c), Assistant, University "HaxhiZeka" \\ rajan.arapi@unhz.eu
}

\section{Doi:10.5901/ajis.2014.v3n2p307}

\begin{abstract}
The preferences and the credibility are some of the aspects that companies take into consideration in planning periods and promotions campaigns. Although in most of the cases the budget is predetermined of media selection, marketers express their beliefs for promotion ways and also media selection. The print and electronic media as two generalized unitsthat include within them a variety of advertising forms, all with special specifications which are relate to the audience targeted by the company. What are the major reasons why companies prefer TV as a medium to advertise their products or services? Why small companies prefer social media respectively internet less than large companies? What is a decisive moment in the selection of media by the companies? These are some of the research questions of this research which aims to identify the media that in this case are more preferred by companies in Kosovo to promote their products and/or services. On the other side, the present research will also identify the problems that companies in Kosovo face during the selection of media, and the obstacles faced by these companies during the advertising process. The importance of advertising in determining the success of the company is related to the selected media. The coordination between the company and the media is made by the marketers which aim to increase the audience in general notwithstanding the audience of these media.
\end{abstract}

Keywords: Media, promotion, advertising,company, product.

\section{The Initial Step of Dealing with the Media by the Companies}

Nowadays there are many sources of media, print media, radio, TV and satellite kablor and websites which compete that will attract the attention of consumers. Logic or planning that companies make in advance about promotion costs is different. A large part of the companies consider spending for advertising as simply expense of which they have gain and not as an investment for the product or service or the company's image. The logic of spending to little for the promotion is a mistake in itself for marketing managers. Spending less many on advertising has an opposite sense of sepending more on advertising budget! This is because no one will notice the advertisement! The essence of all this all this process is to find the average, where profits are kept within the targets, while advertising message will be transmitted properly.

On the other hand if the company spends more money on advertising and overlooks other elements of the marketing mix, then is sure that the advertising would be a wrong investment. Marketers must be careful as well as advertising for the brand image, packaging, creating a perfect product, positive publicity, public relations - media, customer service and treatment.

The media which will be advertised must be chosen according to company's ability to reach the target with a much higher efficiency. Apart from traditional media such as newspapers, magazines, radio, TV and billboard, already widely are used the new media trends including email, telemarketing, online newspapers and magazines, advertising at the point of sale or even advertising in elevators, cafeteria tables, etc. With all these options, choosing the right media has become a major challenge. Besides selecting the media, the marketers should determine the size of the target audience to reach, how often will appear, schedules, etc.. Suppose that you want your ads to be seen by at least $50 \%$ of a target of 1 million people. This means 500 thousand performances. But you would like to see on average for each person to see the advertising 3 times. This brings the number of performances to 1.5 million. But it may take 6 show advertising for any average person to pay attention to advertising it 3 times. This would bring the number of performances at 3 million. Now suppose you want to use a media (billboard) that costs 20 euros for 1,000 performances. In this case, the campaign will cost in total: $20 * 3,000,000 / 1,000=60,000$ euros.

Making such costs comparisons for advertising, in this case can be solved another media that with 60,000 euros will have a higher impact. Often, compromises must be made between audiences, media and budget impac (Menaxhimi portal, Vendimet që duhen marrë rreth 5M-ve të reklamimit, 2013, Shqipëri). 


\section{Thinking and Preliminary Analysis that Companies must make before Choosing the Media for Promotion}

The new model of doing advertising, emphasizes not only the creation of an attractive content, but also finding clever ways to put the promotional message into the texture and platforms where buyers spend time and are active participants.

The determination of the hour of the advertising transmission is made by employees of the media who study the audience and viewership during certain hours. But it should be noted that neither the advertisers who pay more or marketing agents are not sure if the advertising is viewed or notregardless of their ambition and modesty. In Kosovo marketers operate on personal assumptions or guessing. No one make surveys and no one is what they see or what time they see the TV.

The small businesses must take care for advertising in way to progress. If the company wants to do a promotional campaing and the same has a limited budget than the marketers must do a clever choice according to the advertising. The television as one of the most preferred mean for advertising must be excluded because the advertising costs are too high. On the other side there are some very appropriate spaces when we deal with limited budget. The important thing is to identify where the major of the consumer pass their time and find the best ways to realize the promorionalcampaing.

\subsection{Newspapers}

Newspapers give the possibility to reach the notice by many people in a very wide geographical space. Is preferred to choose the specific consumer, by establishing the advertising in a special part of the newspaper, for example in sportive, family or products section. There are some facilities for companies that have a limited budget. In this aspect is reccomandet a designer that makes the advertising more attractive. Usully there are very few seconds before the reader turn the page and for this reason the message must be concise and attractive.

\subsection{Online/E-mail}

The online advertising is very fast and at the same time is global. In this case is better if the product is not limited for a certain geographic area. For example the programming companies can send their product in very few seconds through an email. Is preferred to put the advertising in a search engine, social networks or different websites.

\subsection{Public areas}

In the entire world is preferred to do the advertising in public areas. In these public areas can be placed posters, flyers or even videos of advertising, always with the permission of the relevant state bodies. Even here is preferred to hire a designer to create a poster or advertising slogans such.(Ikub, portal, Si tegjenivendetmëtë mira përtëreklamuarbizneset e vogla, 20.12.2013, Tiranë).

\section{Media Planning Scheme by Companies for Promotion}

With media planning is determined the best way of advertising in the market. The principal aim is to find the connection between the media and marketing agents to transmit the message in the most efficient way to the potential consumers, but always taking into consideration the costs. (George Belch, Michael Belch, ReklamimidhePromovimi, 2007, New York, 303). 


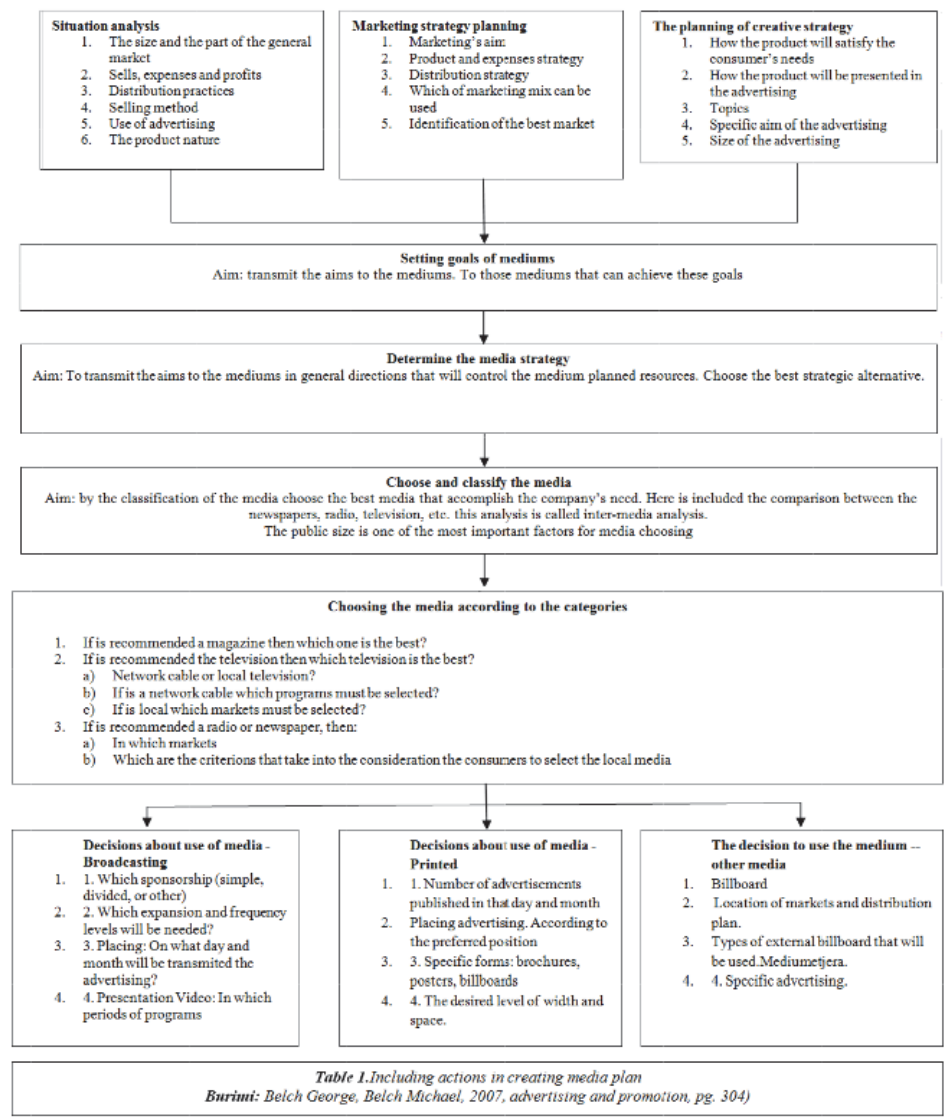

\section{Preferences of Kosovo Companies for Media in Terms of Promoting Products and Services}

One of the key elements that determine the preferences of the companies regarding the media is the targets audiences. In the case of the large and medium companies make their advertising through national televisions and the micro enterprises use the local radios. On the other side is clearly seen that the price plays an important role in the preferences of small enterprises, while the large enterprises pay attention to the preferences of the consumers.

Table 2: The most preferred communication media based to the preferences of companies in Kosovo (Source:Analysis of advertising, 2011, pg 14, MDA, and CDA)

\begin{tabular}{|c|c|c|c|c|c|c|c|c|c|}
\hline & & $\begin{array}{c}\text { TV } \\
\text { (National) }\end{array}$ & $\begin{array}{c}\text { TV } \\
\text { (Local) }\end{array}$ & $\begin{array}{c}\text { Radio } \\
\text { (National) }\end{array}$ & $\begin{array}{l}\text { Radio } \\
\text { (Local) }\end{array}$ & Internet & Newspaper & Cable TV & Otheres \\
\hline \multirow{8}{*}{$\begin{array}{l}\text { Companies } \\
\text { catagorization }\end{array}$} & \multirow{2}{*}{$\begin{array}{c}\text { Large } \\
\text { companies }\end{array}$} & 13 & 3 & 7 & 3 & 5 & 8 & 2 & 0 \\
\hline & & $31.7 \%$ & $7.3 \%$ & $17.1 \%$ & $7.3 \%$ & $12.2 \%$ & $19.5 \%$ & $4.9 \%$ & $0.0 \%$ \\
\hline & \multirow{2}{*}{$\begin{array}{c}\text { Medium } \\
\text { companies }\end{array}$} & 19 & 14 & 8 & 8 & 15 & 11 & 1 & 0 \\
\hline & & $25.0 \%$ & $18.4 \%$ & $10.5 \%$ & $10.5 \%$ & $19.7 \%$ & $14.5 \%$ & $1.3 \%$ & $0.0 \%$ \\
\hline & \multirow{2}{*}{$\begin{array}{c}\text { Small } \\
\text { companies }\end{array}$} & 29 & 33 & 12 & 45 & 38 & 21 & 5 & 8 \\
\hline & & $15.2 \%$ & $17.3 \%$ & $6.3 \%$ & $23.6 \%$ & $19.9 \%$ & $11.0 \%$ & $2.6 \%$ & $4.2 \%$ \\
\hline & \multirow{2}{*}{ Micro companies } & 52 & 98 & 24 & 143 & 77 & 20 & 25 & 19 \\
\hline & & $11.4 \%$ & $21.4 \%$ & $5.2 \%$ & $31.2 \%$ & $16.8 \%$ & $4.4 \%$ & $5.5 \%$ & $4.1 \%$ \\
\hline
\end{tabular}


The interpretation of the research dates for the most preferred communication mediums based to the preferences of the enterprises in Kosovo (table 2) results that the large and medium enterprises choose the national televisions as the most preferred because of the large audience. On the other side the small and micro enterprises preferred the local radios, because they can easlyaccess their local customers and prices are more affordable.

As result of this $50 \%$ the large companies prefer certain companies because of the large audience, and $20.8 \%$ because these media are most preferred by the consumer. The medium enterprises pay more attention but for them are important and the easly access to those mediums. $29.3 \%$ of the small enterprises and $30.8 \%$ of the micro enterprises pay more attention to the to the audience.

Table 3: The preferences of the enterprises in Kosovo for the media

\begin{tabular}{|c|c|c|c|c|c|c|}
\hline & & $\begin{array}{l}\text { Easly } \\
\text { access }\end{array}$ & $\begin{array}{c}\text { Points The large } \\
\text { audience }\end{array}$ & $\begin{array}{l}\text { Preferred by our } \\
\text { consumers }\end{array}$ & $\begin{array}{l}\text { Low } \\
\text { price }\end{array}$ & $\begin{array}{c}\text { Si more } \\
\text { professional }\end{array}$ \\
\hline \multirow{8}{*}{$\begin{array}{l}\text { Companies } \\
\text { catagorization }\end{array}$} & & 4 & 12 & 5 & 1 & 2 \\
\hline & Large enterprises & $16.7 \%$ & $50.0 \%$ & $20.8 \%$ & $4.2 \%$ & $8.3 \%$ \\
\hline & \multirow{2}{*}{$\begin{array}{c}\text { Medium } \\
\text { enterprises }\end{array}$} & 9 & 16 & 6 & 3 & 7 \\
\hline & & $30.0 \%$ & $43.3 \%$ & $10.0 \%$ & $3.3 \%$ & 0 \\
\hline & \multirow{2}{*}{ Small enterprises } & 37 & 39 & 20 & 19 & 18 \\
\hline & & $27.8 \%$ & $29.3 \%$ & $15.0 \%$ & $14.3 \%$ & $13.5 \%$ \\
\hline & \multirow{2}{*}{ Micro enterprises } & 102 & 89 & 26 & 43 & 29 \\
\hline & & $35.3 \%$ & $30.8 \%$ & $9.0 \%$ & $14.9 \%$ & $10.0 \%$ \\
\hline
\end{tabular}

Source: Analysis of advertising, 2011, pg. 16, MDA, CDA

In planning the annual budget for advertising, enterprises except electronic and print media also use other means of advertising. The use of these advertising tools enables these enterprises easier access to certain audiences. Direct contact on a priority basis is selected as the preferred method by $42 \%$, with $21 \%$ leaflets, posters with $20 \%$,billboards with $17 \%$.

Tablea 4. Other advertising tools used by enterprises

\begin{tabular}{|c|c|c|}
\hline What other advertising tools you use & Frequency & Valid percentage \\
\hline leaflets & 141 & $20.91 \%$ \\
\hline Posters & 132 & $19.58 \%$ \\
\hline Billbords & 115 & $17.06 \%$ \\
\hline Direct contacto with the consumers & 286 & $42.43 \%$ \\
\hline
\end{tabular}

Source: Analysis of advertising, 2011, pg. 20, MDA, CDA

The large and medium enterprises in their budget planning include also the advertising in websites. This advertising method is estimated as the most preferred one by the large enterprises with $86.7 \%$ and $51.7 \%$ the medium enterprises. The small and micro enterprises have evaluate this advertising method in a lower level with $30.9 \%$ the small enterprises and with $16.9 \%$ the micro enterprises.

Table 5.

\begin{tabular}{|c|c|c|c|}
\hline & & Yes & No \\
\hline \multirow{8}{*}{$\begin{array}{l}\text { Companies } \\
\text { categorization }\end{array}$} & \multirow{2}{*}{ Large enterprises } & 12 & 2 \\
\hline & & $85.7 \%$ & $14.3 \%$ \\
\hline & \multirow{2}{*}{ Medium enterprises } & 15 & 14 \\
\hline & & $51.7 \%$ & $48.3 \%$ \\
\hline & \multirow{2}{*}{ Small enterprises } & 29 & 65 \\
\hline & & $30.9 \%$ & $69.1 \%$ \\
\hline & \multirow{2}{*}{ Micro enterprises } & 37 & 181 \\
\hline & & $16.9 \%$ & $82.6 \%$ \\
\hline
\end{tabular}

Source: Analiza e tregut tër eklames, 2011, fq. 21, MDA, CDA) 


\section{Market Advertising and Media in Albania}

Television in the Albanian media market continues to be the leader according to the enterprises to promote their products or services. In the meantime as the worldwide this market media in Albania has begun to be affected by the new media, considered as advanced and cheaper for promotion. The social nets and the websites of the companies are listed as the most preferred for advertising. According to Abacus Research November 2012 based to the audience dates and report is noted that the TV medium is decreasing, warning important changes to how it will be spent the budget on media advertising, and the consequences that these changes will bring to the organization's business model of media in a very near future. (ThanasGoga, Era e medias"cross - platform" dhendikimi I sajnëtregun e medias, 2013, Tirana, 4). Despite the current temporary stagnation as a result of the global financial crisis, is noted a significant increase on advertising budgets in recent years, coupled with the already introducing other institutional actors (mainly from the telecommunications sector, financial-banking it, and it's sales retail) advertising market requires more and more investment to performance media publicity techniques afford increasingly sophisticated marketing competition. Generally, the audience's data of the media in Albania serve to three big actors group, that base their activity on the audience (the case of television), listening (case of the radio) and reading (the case of written media). (ThanasGoga, Era e mediasdhendikimi isajnë "cross tregun - platform" e medias, 2013, Shqiperi).

A look at the performance of the Albanian media advertising expenditure (Table 1) indicates that outdoor media type, along with the online are the most recognized platforms.

Table 6: Advertising Market Growth in Albania, 2004-2011

\begin{tabular}{|c|c|c|c|c|c|c|c|c|c|}
\hline Media & & 2004 & 2005 & 2006 & 2007 & 2008 & 2009 & 2010 & 2011 \\
\hline Television & & $86.3 \%$ & $81.1 \%$ & $78.2 \%$ & $63.6 \%$ & $63.8 \%$ & $68.7 \%$ & $65.4 \%$ & $66.8 \%$ \\
\hline Radio & & 1.2 & 1.4 & 1.2 & 1.4 & 1.4 & 1.3 & 1.4 & 1.4 \\
\hline Written media & & 6.4 & 8.1 & 5.8 & 20.1 & 17.8 & 8.5 & 10.7 & 8.5 \\
\hline Outdoor & & 6.1 & 9.4 & 14.3 & 15.6 & 17.4 & 21.8 & 20.8 & 22.4 \\
\hline Cinema & na & & na & na & na & na & na & na & $\mathrm{na}$ \\
\hline Internet & na & & na & na & 0.5 & 0.8 & 1.1 & 0.9 & 0.9 \\
\hline \multicolumn{10}{|c|}{ Advertising market } \\
\hline & & 14.5 & 19.8 & 24.38 & 27.18 & 42.23 & 49.3 & 57.4 & 54.34 \\
\hline
\end{tabular}

Source: Abacus Research, November 2012

Recent data regarding the closing of the 2012 talk generally about a shrinking advertising market ranked between 16$18 \%$ compared with the same period of the last year. Meanwhile in 2013 due to the elections that were held this year in Albania, campaign costs have contributed significantly to the growth of investment in media advertising, reaching values of the 2009 to 2010 , about 50 million euros.

\section{Findings and Recommendations}

Referring to the data from this researchgenerally can be given a statement that clearly creates the basis to prove the hipothesis and the research questions of this paper. What can be said is that Kosovo companies more and more are giving importance to the advertising. Despite of thecompany size, each of them in one form or another try to find alternatives to promote products, services or their image.By analyzing the data for each category of enterprises, we can highlight the specificity and also different preferences of advertising by companies. What can be concluded as a result remains the unsatisfacttion interest and preferences that companies have for socalled other forms of advertising that are the media that generally can be considered as less expensive but also quite reliable in relation to the consumer public.Precisely on this issue I will also relate the following recommendations as a result of what brings this research. Application forms of advertising called indoor and Outdoor Promotion is indispensable for all companies especially for newly introduced companies or ones that tend to enter in a particular market. This form of promotion or advertising involves in itself the direct contact with the consumer in the place where the product is exposed (shops, malls, and other spaces exposure), or even in open spaces (squares frequented by people). The conversations with people, explanations that an authorized person of the company may give, either a casual customer or potential, on the product or what we want to advertise, has the importance and influence greater than most of the media on which this research shows as the 
most favorite.The abovementioned recommendations can be regarded as an adequate solution for companies that do not exactly have to share any big budget for advertising, but also recommended for other companies, those with higher advertising budget, always having in mind the effect that these promotion forms have in relation to customers-audience.

\section{Reference}

Abacus Research, November 2012, Albania

Analysis of the advertising market, 2011, MDA, CDA, Kosovo

Belch George, Belch Michael, 2007, advertising and Promotion, New York.

Ikub, Web, How to find the best places to advertise small businesses, 2013, Tirana.

Management Web, Decisions to be taken about the 5Ms of advertising, 2013, Albania

ThanasGoga, 2013, Media era"cross - platform" and its impact on the media market, Tirana.

VeseliNexhbi, Promotion, 2011, Tetovo

VeseliNexhbi, VeseliTeuta, Marketing Management, 2010, Tetovo 